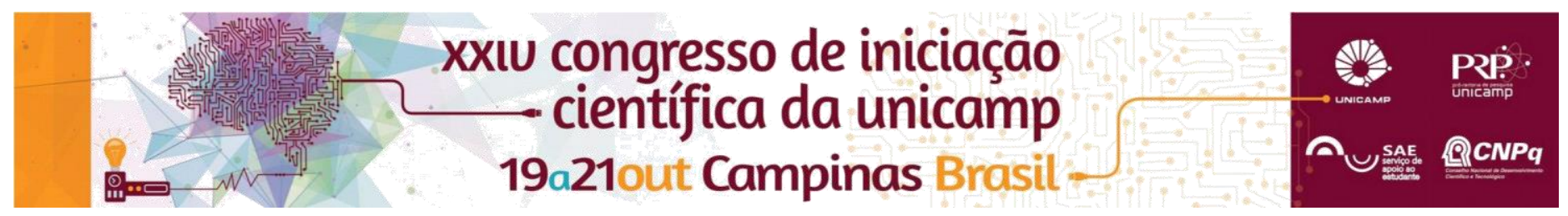

\title{
Diferenças do trote nas escolas médicas brasileiras: análise qualitativa com discentes da graduação
}

\author{
Matheus Andrade Lazzari Becere*, Prof. Dr. Luís Fernando Tófoli
}

\section{Resumo}

Introdução: O trote ocorre em Cursos de Graduação ao redor do mundo a partir da entrada do estudante no ambiente universitário, sendo relacionada com a manutenção da Hierarquia desde a ldade Média. No caso da formação médica, o trote promove situações estressantes para os ingressantes e parece estar relacionado com a hierarquização da carreira e o chamado currículo oculto. Ocorre uma escassez de informações relacionadas as particularidades regionais do trote no Brasil, de sua importância e seus desdobramentos. Objetivos: Este estudo tem como objetivo analisar qualitativamente a opinião dos discentes de diferentes faculdades do Brasil. Buscando entender suas semelhanças, contrastes e desdobramentos. Materiais e Métodos: Levantamento qualitativo das opiniões e informações dadas por discentes por meio de questionário eletrônico aberto. Posteriormente, tais dados serão analisados por meio da Análise de Conteúdo de Bardin. Conclusão: As definições de trote são pouco específicas, abrindo espaço para múltiplas análises e compreensões sobre o fenômeno. As particularidades regionais e os principais dados serão apresentados.

\section{Palavras-chave:}

Trote, educação médica, ritual de iniciação.

\section{Introdução}

Segundo Campo et al.[1], o trote pode ser definido como qualquer atividade requerida implícita ou explicitamente como condição de iniciação ou de contínua participação de uma dada organização, que talvez traga impactos negativos sobre o bem-estar físico e psíquico de um indivíduo. Exemplos não são infrequentes. Todos os anos, a mídia veicula diversas situações de violência contra os ingressantes.

A primeira descrição de abuso nas escolas médicas foi feita em 1982, por Silver [2], correlacionando a mudança no perfil dos estudantes ao longo do curso com a transformação que ocorre em crianças vítimas de violência. No Brasil, pesquisa realizada com os alunos do primeiro, segundo e terceiro ano da Faculdade de Medicina da Pontifícia Universidade Católica de Campinas revela que $75 \%$ dos estudantes afirmam ter sofrido constrangimento durante o trote [3].

O conhecimento superficial do tema por parte dos alunos e da instituição, manifestada pelo desconhecimento de muitos alunos sobre os termos que perpassam o trote (como abuso moral, assédio moral, abuso de poder e etc.) sugerem uma potencial a falta de aprofundamento no tema dentro do currículo médico.

Compreender as particularidades regionais do trote e seus significados é um importante passo na compreensão do fenômeno e no impulso para criação de novos métodos de controle da prática.

\section{Objetivos Gerais}

Este estudo tem o objetivo de analisar as diferentes opiniões dos discentes dos cursos de medicina no Brasil, do ponto de vista qualitativo, a respeito do trote.

\section{Objetivos Específicos}

1. Levantar a opinião dos discentes de diversas faculdades de todas as regiões no que se refere ao trote, suas origens, particularidades e como ele ocorre

2. Análise das potenciais diferenças semelhanças entre as regiões

\section{Resultados e Discussão}

A abordagem qualitativa favorece a análise da percepção dos sentimentos envolvidos na opinião individual e ainda permite, posteriormente, uma análise objetiva da opinião individual.

A coleta de dados foi feita por meio de questionário com perguntas abertas, posteriormente analisadas levando em conta teorias norteadoras.

As perguntas abertas apresentam como temática relevante as seguintes proposições: 1 . Descrição local do trote; 2. Percepção sobre o trote; 3 . Aspectos positivos e negativos do trote; 4. Diferenças regionais; 5 . Origens do trote; 6. Possibilidades de mudança/soluções e abordagens.

(Por exemplo: "Por favor, descreva, sucintamente, caso ocorra, a prática do trote no seu curso. Descreva como ela acontece em geral e como aconteceu no seu caso em particular. ")

A coleta foi feita por meio de plataforma online e de maneira anônima, preservando o sigilo e garantindo a segurança dos entrevistados, apenas considerando a informação sobre a região da faculdade do entrevistado.

\section{Conclusão}

As respostas estão atualmente ainda em análise e serão apresentadas durante o congresso de iniciação científica.

[1]: Campo S, Poulos G, Sipple JW. Prevalence and profiling: hazing among college students and points of intervention. Am J Health Behav. 2005, 29(2):13749

[2]: Silver HK. Medical Students and Medical School, 1982.'

[3] O trote em uma faculdade de medicina: uma análise de seus excessos e influências socioeconômicas, Juliana Cristina Marin et al. Rev. bras. educ. med. vol.32 no.4 Rio de Janeiro Oct./Dec. 2008 